\title{
Ultrastructure and molecular diagnosis of Spironucleus salmonis (Diplomonadida) from rainbow trout Oncorhynchus mykiss in Germany
}

\author{
M. Reza Saghari Fard ${ }^{1,2, *}$, Anders Jørgensen ${ }^{3}$, Erik Sterud ${ }^{3,4}$, Wilfrid Bleiss ${ }^{5}$, \\ Sarah L. Poynton ${ }^{1,6}$ \\ ${ }^{1}$ Department of Inland Fisheries, Leibniz-Institute of Freshwater Ecology and Inland Fisheries, Müggelseedamm 310, \\ 12587 Berlin, Germany \\ ${ }^{2}$ Faculty of Agriculture and Horticulture, Humboldt University of Berlin, Invalidenstrasse 42, 10115 Berlin, Germany \\ ${ }^{3}$ National Veterinary Institute, PO Box 8156 Dep, 0033 Oslo, Norway \\ ${ }^{4}$ Standards Norway, PO Box 242, 1326 Lysaker, Norway \\ ${ }^{5}$ Molecular Parasitology, Institute of Biology, Humboldt University of Berlin, Philippstrasse 13, 10115 Berlin, Germany \\ ${ }^{6}$ Department of Molecular and Comparative Pathobiology, Johns Hopkins University School of Medicine, \\ Broadway Research Building, 733 North Broadway, Room 807, Baltimore, Maryland 21205, USA
}

\begin{abstract}
Diplomonad flagellates infect a wide range of fish hosts in aquaculture and in the wild in North America, Asia and Europe. Intestinal diplomonad infection in juvenile farmed trout can be associated with morbidity and mortality, and in Germany, diplomonads in trout are commonly reported, and yet are poorly characterised. We therefore undertook a comprehensive study of diplomonads from German rainbow trout Oncorhynchus mykiss, using scanning and transmission electron microscopy, and sequencing of the small subunit (ssu) rRNA gene. The diplomonad was identified as Spironucleus salmonis, formerly reported from Germany as Hexamita salmonis. Our new surface morphology studies showed that the cell surface was unadorned and a caudal projection was present. Transmission electron microscopy facilitated new observations of functional morphology, including vacuoles discharging from the body surface, and multi-lobed apices of the nuclei. We suggest the lobes form, via hydrostatic pressure on the nucleoplasm, in response to the beat of the anterior-medial flagella. The lobes serve to intertwine the nuclei, providing stability in the region of the cell exposed to internal mechanical stress. The ssu rRNA gene sequence clearly distinguished S. salmonis from S. barkhanus, S. salmonicida, and $S$. vortens from fish, and can be used for identification purposes. A $1405 \mathrm{bp}$ sequence of the ssu rRNA gene from S. salmonis was obtained and included in a phylogenetic analysis of a selection of closely related diplomonads, showing that $S$. salmonis was recovered as sister taxon to $S$. vortens.
\end{abstract}

KEY WORDS: Diagnosis · Diplomonad - Flagellate · Oncorhynchus mykiss · Rainbow trout • Sequence $\cdot$ Spironucleus salmonis $\cdot$ ssu rDNA $\cdot$ Ultrastructure

\section{INTRODUCTION}

Diplomonad flagellates in fish were first reported from sunbleak Leucaspius delineatus in 1887 (Seligo 1887). Ever since, these organisms have been of interest to protozoologists and parasitologists, and latterly to fish farmers, because of their common occurrence and association with disease. Diplomonads infect a wide range of fish including salmonids, cichlids, gadids, and cyprinids, from freshwater and seawater, in aquaculture and the wild; infections occur in cold, temperate, and warm waters, in North America, Asia, and Europe (Woo \& Poynton 1995).

In salmonids, diplomonad infections are usually found in the intestine and gall bladder (Moore 1922, Davis 1926, Ferguson 1979, Sterud et al. 1997, 1998), 
and can also be systemic (Kent et al. 1992, Poppe et al. 1992, Sterud et al. 2003). Although diplomonad infections in salmonids are commonly reported to be extracellular, intracellular infection is known (Moore 1922, Davis 1926, Sterud et al. 2003). Both intestinal and systemic infections have been associated with high morbidity and mortality in fish in aquaculture (Moore 1922, Ferguson 1979, Kent et al. 1992, Poppe et al. 1992, Sterud et al. 1997).

In young farmed trout, intestinal diplomonad infections are usually associated with chronic low-grade losses, but can also cause acute losses in very small fish (Roberts \& Shepherd 1979). Clinical signs include loss of appetite, excessive nervousness, and long fecal casts (Roberts \& Shepherd 1979, Roberts 1989). Pathology of the gastro-intestinal epithelium is disputed, catarrhal enteritis was reported by Sano (1970) and cytoplasmic blebbing was described by Ferguson (1979). However, in addition to the aforementioned epizootiological data, there is also evidence, from experimental infections, of the pathogenicity of salmonid diplomonads. In experimental infection with diplomonads, juvenile rainbow trout Oncorhynchus mykiss suffered low, but statistically significant mortality, compared to uninfected controls (Uzmann et al. 1965). Diplomonads have often been observed in fish infected with viral haemorrhagic septicemia (VHS). Schlotfeldt \& Alderman (1995) suggest that diplomonads may even be able to act as carriers of VHSV and perhaps of other viral pathogens.

In Western Europe, salmonids are the major group of farmed fish. In Germany, rainbow trout comprise the largest sector of the aquaculture industry, with a production of approximately $25000 \mathrm{t} \mathrm{yr}^{-1}$ (Brämick 2004, Hilge 2004), which places the country among the top 10 producers of rainbow trout worldwide (FAO 2004). In Germany, diplomonads are commonly reported, associated with disease, and yet are poorly characterised. Diplomonads (originally described as Octomitus intestinalis truttae) were first reported from rainbow trout in Germany by Schmidt (1919). Numerous subsequent investigations have been conducted based on light microscopy, including a study of the ecology, host specificity and variability of a diplomonad described as Hexamita salmonis (Sanzin 1965). Several fish pathology texts widely used in Germany refer to the flagellates in trout as $H$. (Octomitus) salmonis (Schäperclaus et al. 1990, Schlotfeldt 1991), and one text cites both Hexamita and Spironucleus as associated with cattharal enteritus in salmonids (Roberts \& Schlotfeldt 1985). Following a taxonomic study of diplomonads in trout by Poynton et al. (2004) the name Spironucleus salmonis should be used as described below.

Taxonomic confusion concerning the identity of diplomonads in fish based on light microscopy studies, has persisted since the 19th century. By light microscopy, 4 diplomonad genera within the family Hexamitidae were reported from fish: Urophagus, Octomitus, Hexamita and Spironucleus. For many years, $H$. salmonis was the commonly used name for diplomonads collected from intestinal infections in salmonids (for further details see Poynton et al. 2004). However taxonomy based on light microscopy has been questioned (for example, Buchmann \& Bresciani 2001, Poynton \& Sterud 2002), and it is now recognised that reliable identification of diplomonads to genus and species is based on ultrastructural features seen by scanning and transmission electron microscopy (TEM and SEM) (Brugerolle 1974, Brugerolle et al. 1973). A recent comprehensive TEM study of a diplomonad from the intestine of rainbow trout from Ireland (Poynton et al. 2004) resulted in H. salmonis (Ferguson 1979) being synonymised with $O$. salmonis Moore (1922) and Davis (1926), and being renamed Spironucleus salmonis. However, detailed SEM studies of $S$. salmonis have not yet been undertaken.

Three additional Spironucleus species from fish have been ultrastructurally characterised: $S$. barkhanus from salmonids (Sterud et al. 1997, 1998), S. torosa from gadids (Poynton \& Morrison 1990, Sterud 1998a,b), and $S$. vortens from cichlids and cyprinids (Poynton et al. 1995). Poynton \& Sterud (2002) suggest that, based on comprehensive electron microscopy observations, all diplomonads from fish belong to the genus Spironucleus. In less detailed ultrastructural studies, 2 further diplomonads have been described from Asian cyprinids (Xiao \& Li 1994, Li 1995). Although reported as Hexamita capsularis and $H$. nobilis, the anteriorly tapering and interwined nuclei are consistent with Spironucleus; to confirm their identity, these species should be examined based on guidelines provided by Poynton \& Sterud (2002).

Molecular characterisation, in addition to ultrastructural characterisation, should play an important role in identifying diplomonad flagellates from fish (Poynton \& Sterud 2002), and linking genotypes with pathogenicity. Molecular diagnosis of diplomonads in salmonids is in its infancy, in contrast to established molecular diagnosis for microsporidia, myxosporea, and monogenea (Cunningham 2002). As part of comprehensive studies on the phylogeny of diplomonads, Keeling \& Doolittle (1997) considered the $\alpha$-tubulin, elongation factor- $1 \alpha$ and the small subunit (ssu) rRNA gene sequences of Spironucleus barkhanus and $S$. vortens. Further genetic characterisation of $S$. barkhanus, namely sequencing of the ssu RNA gene, was undertaken in an epizoological study by Jørgensen \& Sterud (2004). Two genotypes were found, 1 from systemically infected farmed Arctic charr, and 1 from wild Arctic charr Savelinus alpinus. The former pathogenic genotype has now been redescribed as 
Spironucleus salmonicida based on analyses of sequence data from 3 genes: $\alpha$-tubulin, glutamate dehydrogenase 1 (gdh 1) and ssu rDNA (Jørgensen \& Sterud 2006).

To the best of our knowledge, there are no published ultrastructural or molecular studies on diplomonads from German rainbow trout. Therefore we undertook a comprehensive study to characterise them. Our results report and describe Spironucleus salmonis from Germany, provide the first comprehensive SEM study of this flagellate, and present the first sequencing of the ssu rDNA for this parasite, which clearly distinguishes $S$. salmonis from $S$. barkhanus, $S$. salmonicida, and $S$. vortens. Phylogenetic analyses of $S$. salmonis and other closely related diplomonads recovered $S$. salmonis as a sister taxon to $S$. vortens.

\section{MATERIALS AND METHODS}

Source of material. Fingerling rainbow trout were collected from Seltershof farm near Berlin, Germany $\left(12.884^{\circ} \mathrm{E}, 52.061^{\circ} \mathrm{N}\right)$ in $2001,2003,2004$, and 2005 . The fish were transported live from the farm to the LeibnizInstitute of Freshwater Ecology and Inland Fisheries, Berlin (IGB), and subsequently held in quarantine.

Wet preparation of diplomonads. Rainbow trout were decapitated using a scalpel. The body cavity was opened, and the digestive tract was removed by cutting just posterior to the pharynx and anterior to the anus. Fresh intestinal contents from the pyloric region were examined under the light microscope at 200x magnification, and samples from heavily infected fish were used for ultrastructural and molecular studies.

SEM and TEM preparation. All diplomonads were fixed in fresh ( $<2 \mathrm{wk}$ old) $3 \%$ glutaraldehyde in $0.1 \mathrm{M}$ $\mathrm{Na}$-cacodylate buffer (pH 7.4), and held at $4^{\circ} \mathrm{C}$. Subsequently diplomonads were handled either in situ with adjacent intestinal tissue (pyloric region), or as a cell suspension, using 1 of 2 different protocols.

In situ protocol: The pyloric region of heavily infected fish was cut into small pieces (2 to $3 \mathrm{~mm}^{3}$ ), and immediately fixed. After a maximum of 1 wk at $4{ }^{\circ} \mathrm{C}$, post-fixation was begun by centrifuging the tissue at $500 \times g$ for $5 \mathrm{~min}$, followed by rinsing in $0.1 \mathrm{M} \mathrm{Na}-$ cacodylate buffer ( $\mathrm{pH} 7.4$ ) for $3 \times 15 \mathrm{~min}$ at $4^{\circ} \mathrm{C}$. The tissues were placed in $1 \%$ osmium tetroxide in $\mathrm{Na}$ cacodylate buffer for $4 \mathrm{~h}$ at $4^{\circ} \mathrm{C}$, then rinsed again, and transferred to $70 \%$ ethanol for subsequent processing. For SEM processing, the samples were critical point dried using CPD 030, coated with approximately $20 \mathrm{~nm}$ gold in a SCD 005 BAL-TEC, and viewed in a LEO 1430 scanning electron microscope. For TEM, most samples were embedded in Spurr's epoxy resin, sectioned with a diamond knife using an ultracut $\mathrm{S}$ (Leica), stained with uranyl acetate followed by
Reynold's lead citrate, and viewed in a Zeiss EM 900 transmission electron microscope. The other TEM samples were embedded in Eponate (Epon 812) (Ted Pella), sectioned with a Riechert Ultracut E, stained with uranyl acetate followed by lead citrate, and viewed in a Phillips CM 120 transmission electron microscope operating at $80 \mathrm{kV}$.

Cell suspension protocol 1: The contents of the lumen were washed out with fixative, and held for a maximum of $1 \mathrm{wk}$ at $4^{\circ} \mathrm{C}$. After centrifuging at $500 \times g$ for $10 \mathrm{~min}, 2 \%$ melted agarose were added to the pellet, which was put on ice until it solidified. The gel was cut into small pieces $\left(2\right.$ to $\left.3 \mathrm{~mm}^{3}\right)$, and rinsed in $0.1 \mathrm{M}$ HEPES buffer for $2 \times 10 \mathrm{~min}$, and in $0.1 \mathrm{M} \mathrm{Na}$-cacodylate buffer for $1 \times 10 \mathrm{~min}$. The samples were placed in $1 \%$ osmium tetroxide in $0.1 \mathrm{M} \mathrm{Na}$-cacodylate buffer for $1 \mathrm{~h}$ on ice. The gel was rinsed in distilled water for $2 \times 5 \mathrm{~min}$, and then stained in $2 \%$ aqueous uranyl acetate for $1 \mathrm{~h}$. For TEM, the samples were then dehydrated, embedded in Eponate (Epon 812) (Ted Pella), sectioned with a Reichert Ultracut E, stained with $2 \%$ uranyl acetate (aq) for $20 \mathrm{~min}$, followed by lead citrate, and viewed in a Phillips CM 120 transmission electron microscope operating at $80 \mathrm{kV}$.

Cell suspension protocol 2: The pyloric region of the intestine was closed at both ends with a thread, filled with fixative via a syringe (via a portal made by cutting off 1 of 2 distinct large anterior pyloric caeca), and immersed for $3 \mathrm{~d}$ in fixative at $4^{\circ} \mathrm{C}$. After fixation, the contents of the lumen were washed out using fixative and a 20 guage syringe. The samples were then centrifuged and post-fixed in $1 \%$ osmium tetroxide in $0.1 \mathrm{M}$ cacodylate buffer $(\mathrm{pH} \mathrm{7.4)}$ ) for $1 \mathrm{~h}$ and $15 \mathrm{~min}$, and finally dehydrated in a graded ethanol series. In preparation for SEM, the diplomonads were dispersed on a Millipore filter-paper using a syringe equipped with a filter-paper holder, before critical point drying and gold coating (Sterud 1998b). The specimens were viewed in a JEOL JSM 6400 scanning electron microscope equipped with a MegaView III Soft Imaging System. For TEM, the samples were centrifuged to a pellet and embedded in LX 100 resin. Ultra-thin sections were stained with lead citrate and uranyl acetate and viewed in a Philips CM100 transmission electron microscope equipped with a MegaView III Soft Imaging System.

Identification guidelines. Interpretation of ultrastructure followed the guidelines of Poynton \& Sterud (2002), and the recent ultrastructural description of Spironucleus salmonis (Poynton et al. 2004).

Extraction of DNA, cloning of PCR products, and sequencing of ssu rDNA. The intestines of 2 infected rainbow trout fingerlings were preserved in 96\% ethanol. An aliquot of $1 \mathrm{ml}$ ethanol preserved digesta was resuspended in $13 \mathrm{ml}$ phosphate-buffered saline 
(PBS), and pelleted by centrifugation at $2000 \times g$ for $10 \mathrm{~min}$. The PBS was discarded and the pellet resuspended in $200 \mu \mathrm{l}$ of PBS. The DNA extraction was performed according to the QIAamp DNA Stool Mini Kit protocol (Qiagen). The DNA was eluted in $200 \mu \mathrm{l}$ of Buffer AE (Qiagen).

The ssu rDNA fragment from the diplomonad was amplified using primers Spiro-1f (5'-AAG ATT AAG CCA TGC ATG CC-3') and Spiro-2r (5'-GCA GCC TTG TTA CGA CTT CTC-3') as described by Jørgensen \& Sterud (2004). The PCR products were cloned using the TOPO TA cloning kit (Invitrogen).

Five positive clones were picked and sequenced in each direction. The sequences of the primers used in sequencing are shown in Table 1. All products were sequenced using the DYEnamic ET dye terminators, and analysed on a MegaBACE (1000) analysis system (Amersham Biosciences). All sequencing products were purified using Autoseq ${ }^{\mathrm{TM}} \mathrm{G}-50$ columns (Amersham Biosciences).

Alignment and phylogenetic analyses. The ssu rDNA sequence from 2 isolates of Spironucleus salmonis from rainbow trout in Germany was aligned, using Bioedit (Hall 1999), against corresponding sequences from S. barkhanus isolated from wild Arctic charr Salvelinus alpinus (GenBank Accession No. AY646679), Spironucleus salmonicida isolated from farmed Atlantic salmon Salmo salar (AY677182), Spironucleus vortens isolated from angel fish Pterophyllum scalare (U93085), Hexamita inflata, free-living (L07836), Hexamita sp. free-living (Z17224), Giardia ardeae isolated from birds (Z17210), and Octomitus intestinalis isolated from mouse Mus musculus (DQ366277). The alignment was manually checked for misaligned bases and positions with gaps removed.

The resulting alignment was subjected to phylogenetic analyses using maximum likelihood (ML), minimum evolution (ME), and maximum parsimony (MP). All analyses were conducted using PAUP (Swofford 2002). The hierarchical nested likelihood ratio test, implemented in Modeltest (Posada \& Crandall 2001), was used to select the best-fit model of nucleotide sub-

Table 1. Sequencing primers used to sequence partial small subunit (ssu) rRNA genes obtained from diplomonads from rainbow trout Oncorhynchus mykiss

\begin{tabular}{|ll|}
\hline Primer & Sequence $\left(5^{\prime}-3^{\prime}\right)$ \\
\hline Salmonis 1f & TTGTGTACGAGGCAGTGACG \\
Salmonis 2f & TCCCCGGTTCGTTGGTCAAG \\
Salmonis 3f & GTTAACGAGCGAGATGGACT \\
Salmonis 4r & CGATCCATGGAAATTGATCC \\
Salmonis 5r & GTCTAGCCCCACGATAACGC \\
Salmonis 6r & TAAGTGACTCACGACGCCTC \\
\hline
\end{tabular}

stitution. The Tamura-Nei nucleotide substitution model with gamma-distributed rate variation $(\operatorname{TrN}+\mathrm{G})$ was found to produce optimal ML settings. The shape parameter $(\alpha)$ of the gamma distribution (4 rate categories) was estimated to be 0.689 . The same substitution model was also used in the ME analysis. The MP was conducted using default settings in PAUP. A heuristic tree search using 10 random taxa additions and the branch-swapping algorithm, tree bisectionreconnection (TBR), was used for all analyses. Bootstrap resampling of 500 replications was used for the ML analyses, while 1000 replications were used for ME and MP to examine the confidence of the nodes within the resultant tree topologies.

\section{RESULTS}

\section{Surface morphology}

The flagellates were pyriform, with a posterior end that was more or less tapered, and bore a caudal projection; the surface of the body was unadorned (Fig. 1). In some flagellates, the surface was not completely smooth, with some rounded swellings reaching about $0.3 \mu \mathrm{m}$ in diameter (Fig. 1b), and discharging vacuoles reaching about $0.4 \mu \mathrm{m}$ in diameter (Fig. 1c). The recurrent flagella emerged from the body on both sides of the caudal projection (Fig. 1d,e).

\section{Internal structure}

Identification to genus

The 2 elongate nuclei tapered anteriorly and were multi-lobed and intertwined apically (Fig. 2a-c). The 2 recurrent flagella passed posteriorly between the 2 nuclei (Fig. 2d), and each recurrent flagellum was surrounded by a flagellar pocket. Kinetosomes (syn. basal bodies) lay anterior-medial to the nuclei at the apex of the cell (Fig. 2e). Kinetosomes of 2 anterior flagella (k1, $\mathrm{k} 3)$ and 1 recurrent flagellum $(\mathrm{kr})$ were close to each other, and made a triangle form (Fig. 2f). There was a right angle between $\mathrm{k} 1$ and $\mathrm{kr}$, and $\mathrm{k} 3$ lay between at an angle of $45^{\circ}$ to both (Fig. 2f).

\section{Identification to species: cytoskeleton}

Supra-nuclear microtubular bands extended over the anterior of the nuclei, closely following the nuclear membranes (Fig. 2e). Infra-nuclear microtubular bands ran along the medial surface of the nuclei to the opening of the striated lamina surrounding the recurrent 

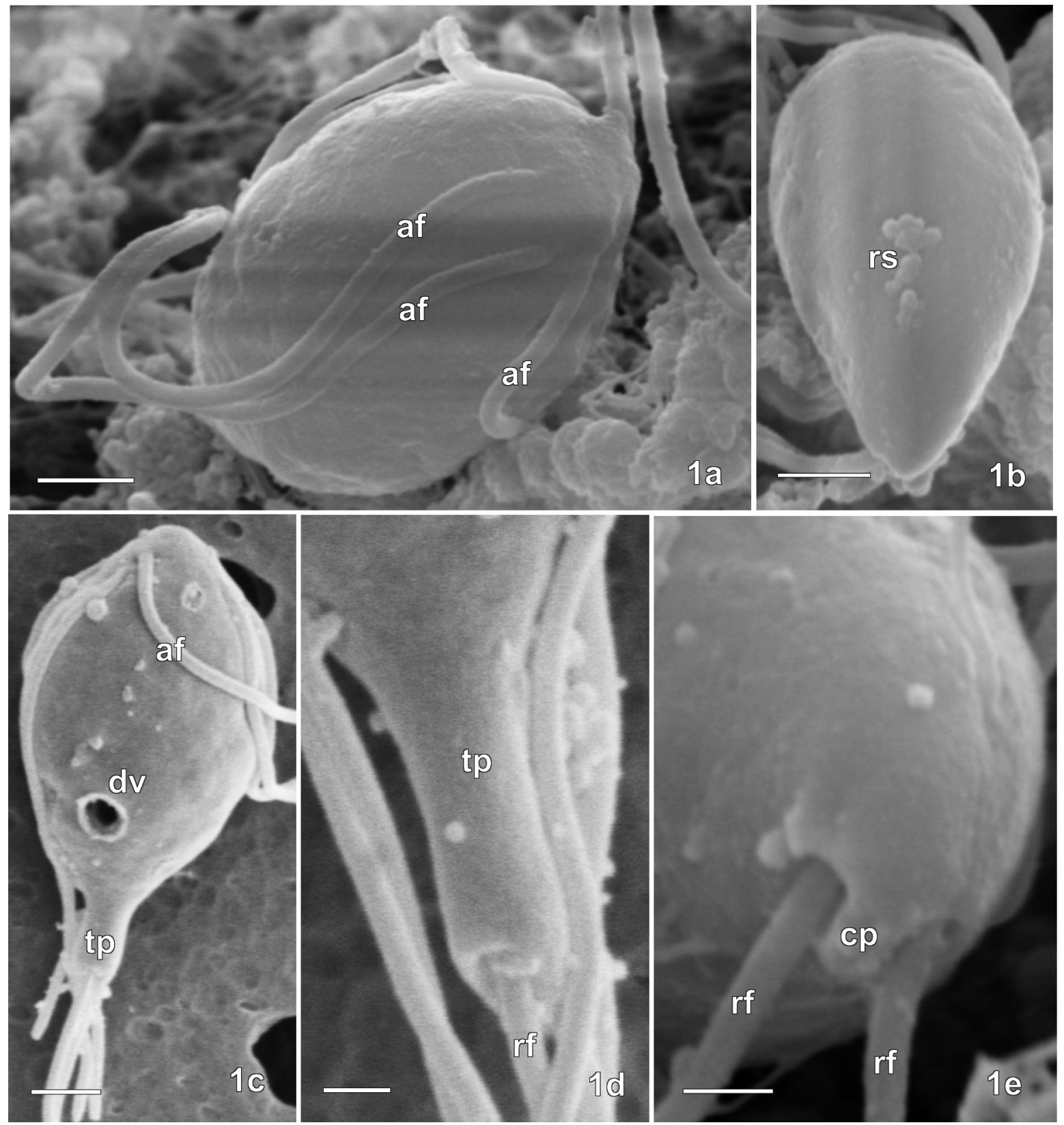

Fig. 1. Spironucleus salmonis infecting Oncorhynchus mykiss. Scanning electron micrographs of diplomonad flagellate from intestine of fingerling rainbow trout showing surface architecture. (a) Anterior-lateral view of flagellate showing unadorned surface, with set of 3 anterior flagella (af). (b) Dorsal or ventral view of flagellate showing rounded swellings (rs). (c) Lateral view of flagellate showing anterior flagella (af), tapered posterior end (tp), and discharging vacuole (dv). (d) Lateral view of flagellate showing tapered posterior end (tp), and an emerging recurrent flagellum (rf). (e) Posterior end of flagellate showing recurrent flagella (rf) that emerged from body on both sides of caudal projection (cp). Scale bars = (a,b) $1 \mu \mathrm{m}$, (c) $2 \mu \mathrm{m},(\mathrm{d}, \mathrm{e}) 0.5 \mu \mathrm{m}$

flagella (Fig. 2d). Direct microtubule bands radiated from the opening of the striated lamina (Fig. 2d).

In transverse section through the middle of the cell, posterior to the nuclei, the 3 microtubular bands accompanying the recurrent flagella radiated at the opening of striated lamina (Fig. 3a,b). The radiate pattern of microtubular bands comprised (from left to right in Fig. 3a,b) an undulating row of 4 microtubules lying between the tip of the striated lamina and extending into the opening of the striated lamina (direct band), a straight row of 3 microtubules radiating away from the opening of the striated lamina (direct band), and a curved row of 7 microtubules extending over the distended side of the striated lamina (infra-nuclear band) 

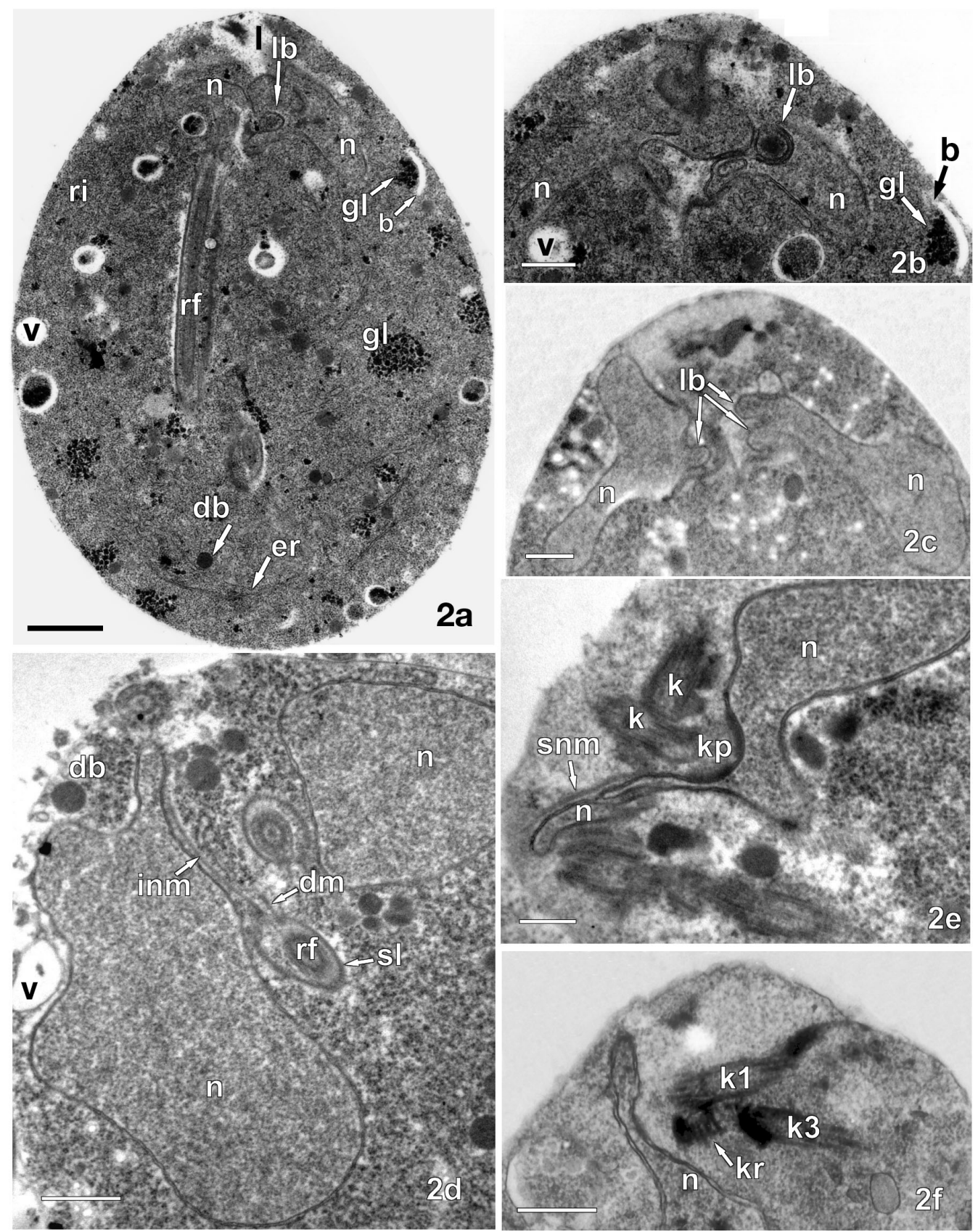

Fig. 2. Spironucleus salmonis infecting Oncorhynchus mykiss. Transmission electron micrographs of diplomonad flagellate from intestine of fingerling rainbow trout showing features for identification to genus. (a) Longitudinal section through cell showing the 2 elongate nuclei (n) that are S-shaped, and multi-lobed (lb); note recurrent flagellum (rf), light-staining homogenous cytoplasm (l) in the apex, numerous free ribosomes (ri), bowl-shaped membranous structure (b), aggregation of glycogen (gl), endoplasmic reticulum (er), electron-dense bodies (db), and vacuoles (v). (b) Longitudinal section through the apex of cell showing that the 2 nuclei (n) are multi-lobed (lb), and intertwined apically; note bowl-shaped membranous structure (b) with closely oppressed aggregation of glycogen (gl), and vacuoles (v). (c) Longitudinal section through apex of cell showing that the 2 nuclei (n) are multi-lobed (lb) and intertwined apically. (d) Transverse section through anterior of cell showing the 2 recurrent flagella (rf) pass posteriorly between the 2 nuclei (n); infra-nuclear microtubular bands (inm) run along medial surface of nuclei to opening of striated lamina (sl) surrounding the recurrent flagella; direct microtubular bands (dm) radiate from opening of striated lamina; note electron-dense bodies (db) and vacuoles (v). (e) Oblique section through kinetosomes (k) lying anterior-medial to nuclei (n) at apex of cell; the base of a kinetosome lies in the cup-shaped kinetosomal pocket (kp); note supra-nuclear microtubular bands (snm) extended over anterior of nuclei, closely following nuclear membranes. (f) Oblique section through kinetosomes of the 2 anterior flagella $(\mathrm{k} 1, \mathrm{k} 3)$, and 1 recurrent flagellum (kr) close to a nucleus (n) at apex of cell; note right angle between k1 and $\mathrm{kr}$ and that $\mathrm{k} 3$ lies between them at an angle of $45^{\circ}$ to both. Scale bars $=(\mathrm{a}) 1 \mu \mathrm{m},(\mathrm{b}, \mathrm{c}, \mathrm{d}, \mathrm{f}) 0.5 \mu \mathrm{m},(\mathrm{e}) 0.25 \mu \mathrm{m}$ 

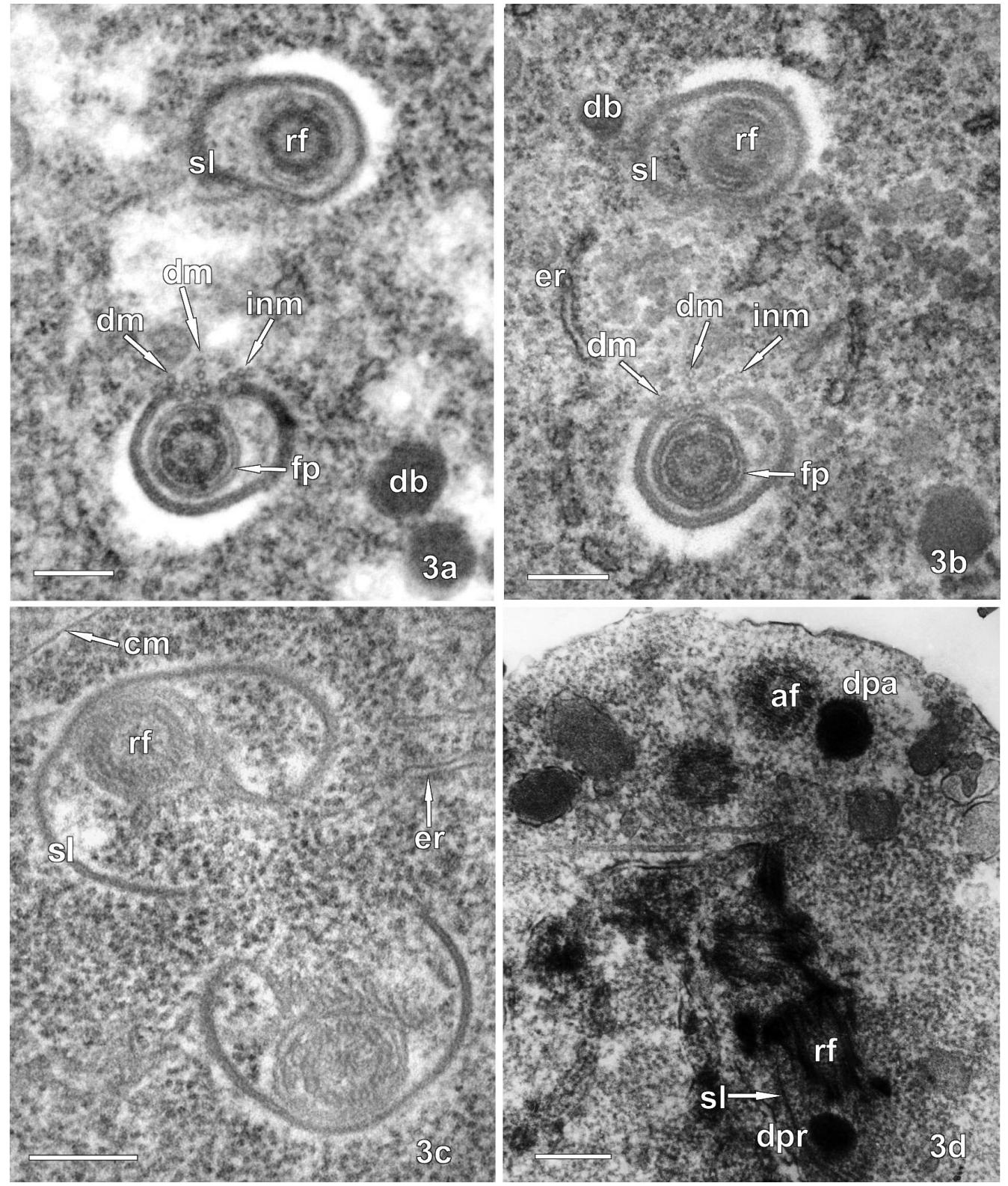

Fig. 3. Spironucleus salmonis infecting Oncorhynchus mykiss. Transmission electron micrographs of diplomonad flagellate from intestine of fingerling rainbow trout showing cytoskeletal features for identification to species. (a) Transverse section through middle of cell, posterior to nuclei, showing radiated pattern of 3 microtubular bands at the opening of striated lamina (sl) surrounding flagellar pocket (fp) and recurrent flagellum (rf). The 3 microtubular bands comprise (from left to right): undulating row of 4 direct microtubules $(\mathrm{dm})$ lying between tip of striated lamina and extending into the opening of the striated lamina; straight row of 3 direct microtubules $(\mathrm{dm})$ radiating away from opening of striated lamina; and curved row of 4 infra-nuclear microtubules (inm) extending over distended side of striated lamina; note electron-dense bodies (db). (b) Transverse section through middle of the cell, posterior to nuclei, showing radiated pattern of 3 microtubular bands at opening of striated lamina (sl) surrounding flagellar pocket (fp) and recurrent flagellum (rf), undulating row of 4 direct microtubules (dm) lying between tip of striated lamina and extending into opening of the striated lamina, straight row of 3 direct microtubules $(\mathrm{dm})$ radiating away from opening of striated lamina, and curved row of 7 infra-nuclear microtubules (inm) extending over distended side of striated lamina; note the endoplasmic reticulum (er) around the 2 recurrent flagella, and electron-dense bodies (db). (c) Transverse section through the 2 recurrent flagella (rf), lying close to each other at posterior end of cell; asymmetrical U-shaped striated lamina (sl) is expanded; note adjacent cell membrane (cm). (d) Oblique section through anterior part of cell; an electron-dense plaque (dpa) lies adjacent to an anterior flagellum (af), and another electron-dense plaque (dpr) lies posterior to basal portion of the recurrent flagellum (rf), between the axoneme and striated lamina (sl); the dense plaques in this figure are circular (a shape also consistent with dense bodies) because of the oblique section; however, note the precise position of 'dpa' and 'dpr', and their darkly staining structure, which confirms these structures as dense plaques. All scale bars $=0.25 \mu \mathrm{m}$ 
(Fig. 3a,b). The flagellar pocket was surrounded by an asymmetrical U-shaped striated lamina when viewed in transverse section (gutter-shaped in 3 dimensions) (Fig. 3a,b). At the extreme posterior end of cell, the U-shaped striated lamina was expanded when viewed in transverse section (Fig. 3c).

Electron-dense plaques were visible at the anterior part of the cell (Fig. 3d). An electron-dense plaque lay adjacent to anterior kinetosome, and another lay just posterior to the basal portion of the recurrent flagella, between the axoneme and the striated lamina (Fig. 3d). These dense plaques are distinguished from dense bodies by their precise position in the cytoplasm, their darkly staining structure, and their size and shape (as described by Poynton et al. (2004) for Spironucleus salmonis from rainbow trout in Ireland).

Identification to species: cytoplasm

The cytoplasm of the flagellate had a light-staining homogenous region in the apex (Fig. 4a), and an organelle-rich heterogeneous region in the rest of the cell (Fig. 2a). Heterogeneous cytoplasm contained numerous free ribosomes, bowl-shaped membranous structures, aggregations of glycogen, endoplasmic reticulum, electron-dense bodies, and vacuoles (Figs. 2a,b \& $4 \mathrm{a})$. The aggregations of glycogen were present in at least 3 distinct locations, i.e. some glycogen was irregularly scattered throughout cytoplasm (Fig. 2a), some glycogen lay within the bowl-shaped membraneous structures (Fig. 4a), and some glycogen was distributed longitudinally between the flagellar pocket and striated lamina (Fig. 4a). Endoplasmic reticulum was distributed irregularly in the cytoplasm and around the recurrent flagella (Figs. 2a \& 4c). One membranebound electron-dense body was extended adjacent to endoplasmic reticulum, and appeared as 3 interconnected dense bodies (Fig. 4b); another was elongate in section (Fig. 4c). Some electron-dense bodies were completely membrane bound (Fig. 4d), some had the same high contrast material at the periphery (Fig. 4e), while others did not appear to have a membrane (Fig. 4d). A discharged vacuole was visible just beneath the cell membrane (Fig. 4f).

\section{Molecular characterisation}

An approximately 1400 bp fragment was amplified from diplomonads from 2 rainbow trout and cloned. The pair-wise variations between the 5 sequenced clones from 1 fish comprised on average 4 out of 1405 positions. The pair-wise variations between clones from 2 individual fish also comprised on average 4 .
Two consensus sequences were constructed from the 5 clones obtained from each fish: S.s-1 (Accession No. DQ394703) and S.s-2 (Accession No. DQ394704).

Based on an alignment of ssu rDNA from 2 isolates of Spironucleus salmonis from rainbow trout against S. barkhanus from wild Arctic charr, S. salmonicida from farmed Atlantic salmon, and $S$. vortens from angelfish, pair-wise similarities were calculated for 1441 positions (Fig. 5). S. salmonis from German rainbow trout was $75.1 \%$ similar to $S$. vortens from angelfish, and only 65.95 and $65.45 \%$ similar to $S$. barkhanus and $S$. salmonicida, respectively.

\section{Phylogenetic analyses}

The alignment of the ssu rDNA from one isolate of Spironucleus salmonis (DQ394703) and closely related diplomonads consisted of 1235 characters when positions with gaps were removed. The resulting alignment was subjected to phylogenetic analyses using ML, ME and MP. All tree-building methods produced the same topology (Fig. 6). S. salmonis was recovered as a sister taxon to $S$. vortens with strong bootstrap support. S. salmonicida and $S$. barkhanus appeared as the most basal taxa of the Hexamitinae sequences included. The position of Hexamita inflata and Hexamita sp. in the tree causes the paraphyly of Spironucleus with modest bootstrap support.

\section{Deposition of materials}

A SEM stub (181-1) and a TEM block (2730-1) have been deposited at the Norwegian School of Veterinary Science (PO Box 8146 Dep., 0033 Oslo, Norway). The sequence of Spironucleus salmonis has been submitted to Genbank under Accession Nos. DQ394703 (Isolate 1) and DQ394704 (Isolate 2).

\section{DISCUSSION}

Ultrastructural examination of diplomonad flagellates from the intestine of rainbow trout from Germany showed them to be Spironucleus salmonis (according to Poynton et al. 2004), confirming the presence of this parasite for the first time in Germany. Our study provided comprehensive characterisation of $S$. salmonis, including new details of surface ultrastructure, particularly recognition of the caudal projection. We also revealed new aspects of functional morphology of the cell. The ssu rRNA gene sequence from $S$. salmonis is clearly different from those of other piscine Spironucleus spp. 

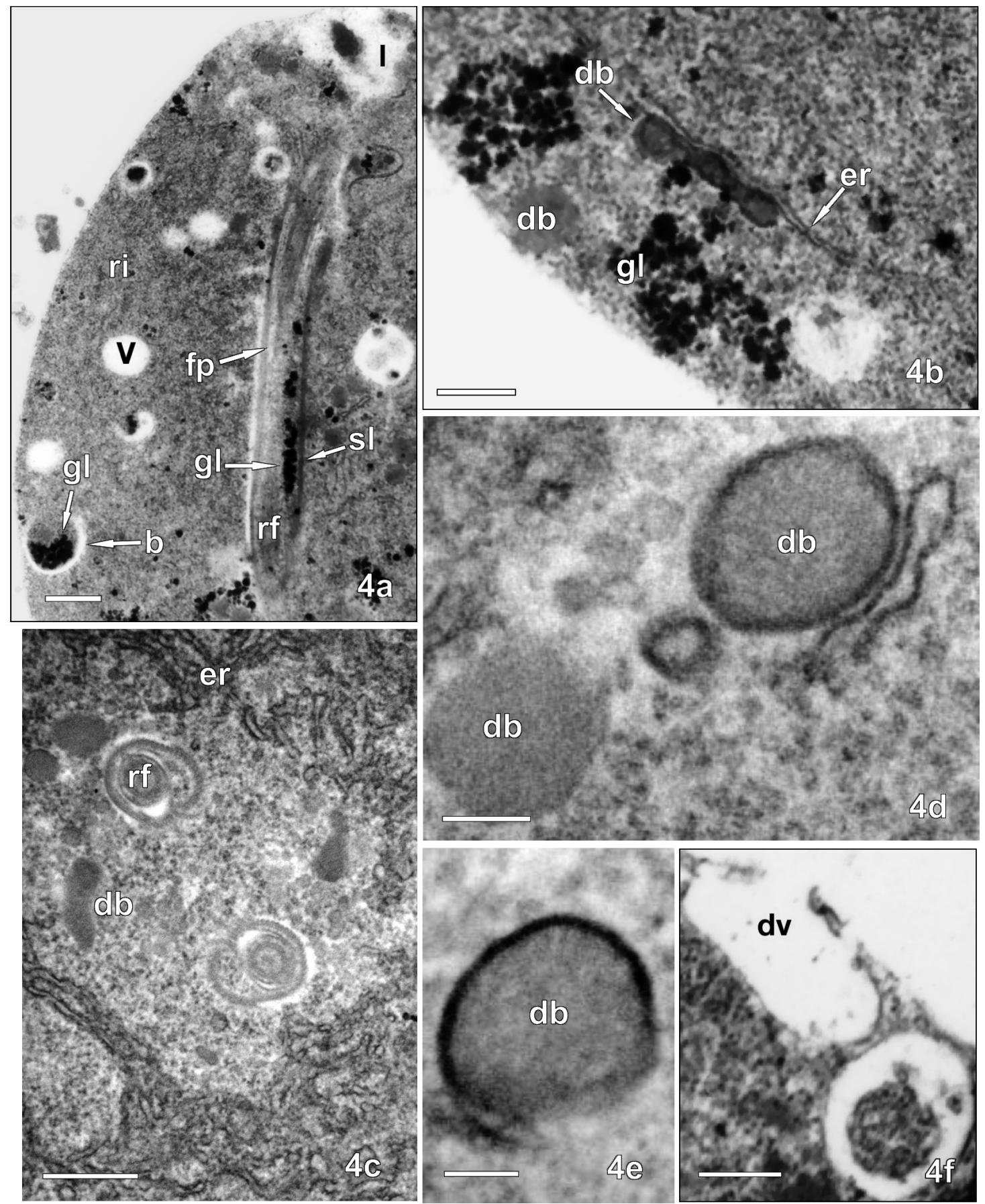

Fig. 4. Spironucleus salmonis infecting Oncorhynchus mykiss. Transmission electron micrographs of diplomonad flagellate from intestine of fingerling rainbow trout showing cytoplasmic features for identification to species. (a) Longitudinal section through body showing light-staining homogenous region (l) in apex, and a recurrent flagellum (rf) passing through middle of cell. Some glycogen (gl) is irregularly scattered throughout cytoplasm; some glycogen is distributed longitudinally between the flagellar pocket (fp) and striated lamina (sl), and some glycogen lie within bowl-shaped membranous structures (b); note numerous free ribosome (ri), and vacuoles (v). (b) Longitudinal section through body showing one membrane-bound electron-dense body (db) which is extended adjacent to endoplasmic reticulum (er) and appears as 3 interconnected dense bodies; note aggregations of glycogen (gl), and non membrane-bound electron-dense body (db). (c) Transverse section through middle of cell showing 2 recurrent flagella (rf) surrounded by irregularly distributed endoplasmic reticulum (er); note also electron-dense bodies (db), one of which is elongate. (d) One electron-dense body (db) that is completely membrane bound (right), and another electron-dense body that does not appear to have a membrane (left). (e) Electron-dense body (db) with high contrast material at the periphery.

(f) Discharged vacuole (dv) beneath cell membrane. Scale bars $=(\mathrm{a}, \mathrm{c}) 0.5 \mu \mathrm{m},(\mathrm{b}, \mathrm{f}) 0.25 \mu \mathrm{m},(\mathrm{d}, \mathrm{e}) 0.125 \mu \mathrm{m}$ 
s.s-1 AAGCAAGCC- ---ACGGCGA AGCGTTGTAC GGCTCATTAG ATGCGTTCTC 50

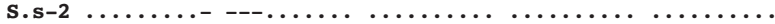
s.v .GA..GCAT- --G.CTG. .СTCGCAA. . ........ ........ s.b .TT..TTATT GTGGA.CAA. .A..GC.A.. A......T ......G..A S.sc .TT..TTATT GTGGA.CGA. GA..GC.A.. A......T ..CA..GG.T s.s-1 ATGTATCTGC T-GTTACCCC AGTTGAAtAA CCTGAGCAAC TCCCACGCTA 100

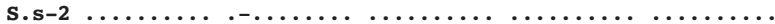
s.v ….GGC. CCA...T-. ...G.G... .......... .T.... s.b ...GCA.A. AATG..TTT. -....G...G TAACG.A..A ..TGTTAG.

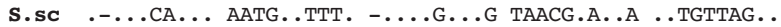

s.s-1 ATGCGTGAAT CCGAGTAGCC TCAGTACGAT ACGGGCTTAG TCCGTGCCGA 150

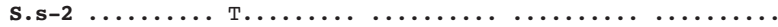
s.v ..A.CG.C. TT...G.TT. AGTA.TGA.. .T..A-... G.G...TTT s.b …..... TGTTT.TAG. ATTA.GTT.A .AATA-A... .АA....GAT S.sc ..A.A.... TATGT.TAGT ATTC...T.A .GATA-A... .АA..А.GTT s.s-1 TGGACAGCAG ATCAGGTTCG CGTGCATCAC CTT--GACGG TAGGGTAATG 200

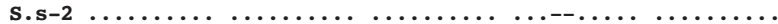
s.v ..AGGG.GCA T.GT.A... .AC.........--.TA........

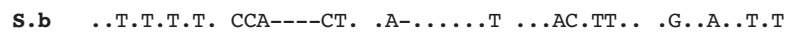

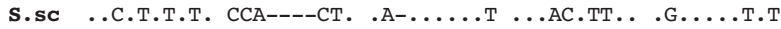
s.s-1 GCCTACGGTG GGATTAACGC AC-ACGGGGT GTTAGGGCAC GACTCCGGAG 250

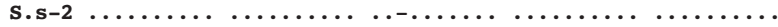
s.v TG..Т.СТА. ….... СТ-.... АС А.....

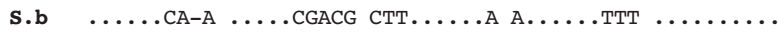

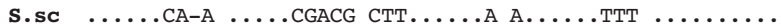

s.s-1 AatGAGCATG AGAGACGGCT CAtAgtTCTA AgGAAgGCAG CAGGCGCGGA 300

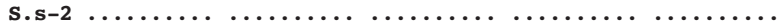

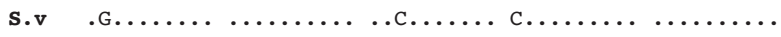

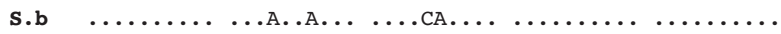

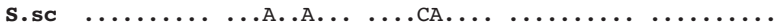

s.s-1 AATTGCCCAA TGTAC-CGTT GTGTACGAGG CAGTGACGAG GCGTCGTGAG 350

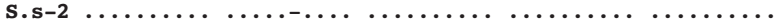

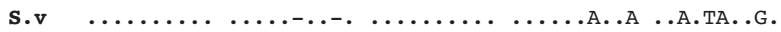
s.b $\ldots \ldots \ldots \ldots$......... T.A.............. AAA.G..AG. s.sc $\ldots \ldots \ldots \ldots \ldots$. . TT.-- ................ AAA.GAA.G.

s.s-1 TCAC-TTAGg -TGACATTAC GATGAGTGAG GTGTACAGAC CCTCGCAAAT 400

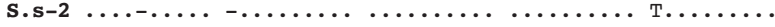
s.v CTGGCG..A. C.AG..C.GT ......... TC...... . G.C.TT..C s.b CACT-..T-. -.-G..C..T CGA.G..T.. TG...TCTTT G..AA.CG-. S.SC .АСТ-..T-. -._..СС.T СTA.G.ССT. T.A..TCT.A G..AA.CGG.

s.s-1 GCAAGTCGTG GGAAAGCATG GTGCCAGCAG CCGCGGTAAT TCCATCATGA 450

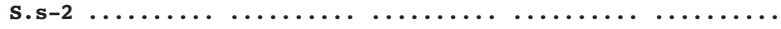

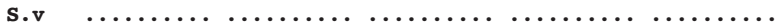

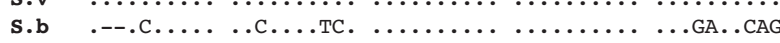

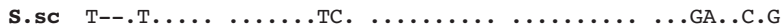

s.s-1 CTAACTCATT CTTACGGTGC TGCAGTTAAA GCGTCCGTAG CTGGCGGCC- 500

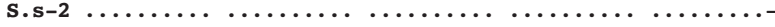
s.v ..G..АATCC ................. А..СT.......... .TTG s.b GG.GT.TTCC A..TG.T.................. T.TA.T.A.s.sc AG.GTATTC. A..GT.T.................. T.TATTTT.-

s.s-1 ------ -TGCCGACTC GAGGAACTCT CGACGCCCAA CGTAGCGAGC 550 S.s-2 s.v CCGAAGAAт тC............. s.b ------T C.TT.АСTAT A..С..AG.C GA.T..T.C. ---.ТTTTT

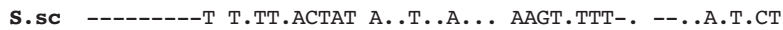

s.s-1 GCG-GTGAGC TGCAGCGAGT TACGGCAACA ACAACTAT-C GCTATAGGAC 600

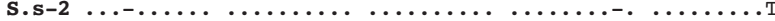

s.v ...T.A.G.. .TA...... G.T.....G TGT.T.GCGT .GCC...AGA s.b TA.CAGT.TT .AT. .TAT.A A.TTAT.G.G CGG--C..TG AACG...TTT

S.sc TAACTGTTTT .АT..TAT.A A.TTAT..TG CGG--...TT .GCG...TTT

s.s-1 AGGGGAAGG TCCTTCTATT ATAGGGGAC AGGTGAAATA GGATGATGCC 650

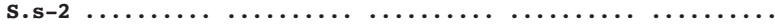

s.v GCCA.G.C.. C.AC...C. .GC..A.................

s.b $\quad \ldots \ldots-1 . . . . . . \ldots \ldots \ldots \ldots$.

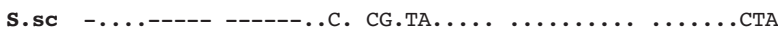

s.s-1 TATAGGAGGA ACAAGTGCGC AGGCACTGAG TC-GTCCCCG GTTCGTTGGT 700

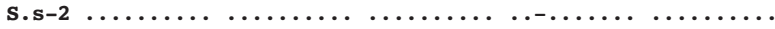

s.v .C..A.... T.GGC...T .A..TG..G. AGAC.GTG.T C..GC.-..

s.b .CG.A..CCC ..GGTA...G .... . .CC.A CGAAGT..AA ..GTCAC.A.

s.sc .CG.A..CC. ..GGTA...G ....T.CC.A CGCAGT.TAA ..ATCAC.A.

s.s-1 CAAGGGCGTT ATCGTGGGGC TAGACGATGA TTAGAGACCG TTTTACTCCA 750

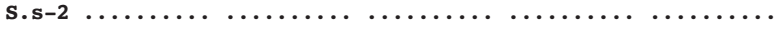

s.v ..T.A..AG .G..CA.......................TG

s.b $\ldots$. AA.TAA .GTCA.... $\ldots \ldots$. . . . . . . . . . . . .

s.sc ....AA.TAA .GTCA...A .................... s.s-1 CGTCGTAAAC GATGCTACCT CGCTGTGCGC TGTTCAAACA CGTGCTTAGC 800

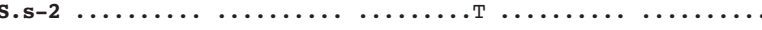
s.v ..C.C............С TTT........ .АGCACTG.T A......... s.b GAC.C........ .TCG... A....-AT.G GA..TTT--T --.СА..T. s.sc GAC.C.........TCG... A....-AT.G G...TTT..T --.CA..T..

s.s-1 GAAGAGAAAT CG--AAGTGT ACGA-CCCCT GGGGGGAGTA TGCTCGCAAG 850

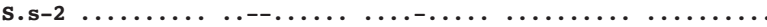

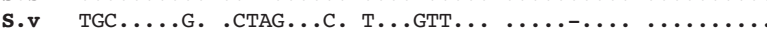
S.b C................ T.AGA.T.-. ............. S.sc C................ T.AGA.T.-..............

s.s-1 GGTGAAACTT GAAAgTATTG ACGGAAAGA ACCACCAGAC GTGGAGTCTG 900

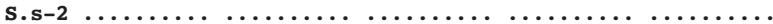

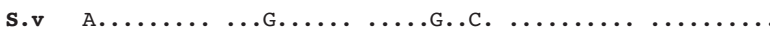

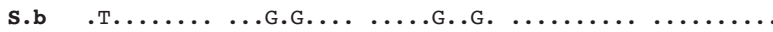

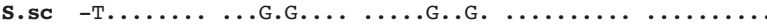

s.s-1 CGGCTTAATT TGACTCAACG CGCCAATCTT ACTAGACCCA GATGCTTTAC 950

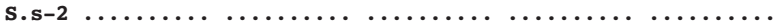

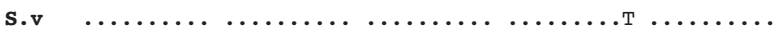

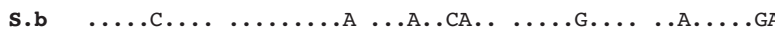

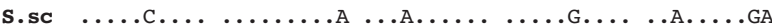

s.s-1 TGTACGTCAG ACTGAGAGAT CTTACATGAA TGAGCAGGTG GTGGTGCATG 1000

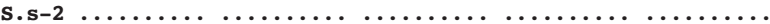
s.v $\quad \ldots \ldots \ldots$. т..т. s.b G.АTT.А................ .А.ТT.т......... S.Sc G.АTT.А......... ....... .А..ТT.Т........

s.s-1 GCCGCTCTTA GTTCGTGGTG TGAACTGTCT GCTTCATTGC GTTAACGAGC 1050

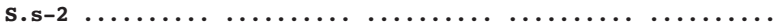

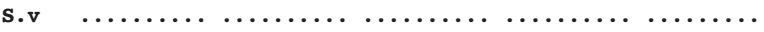
s.b ……..... .А.Т... ............... S.sc ……....... .А...................

s.s-1 GAGATGGACT T-GTGGATCA ATTTCCATGg ATCGCCAGTG AAGAGCTGGA 1100

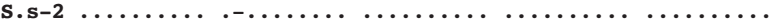

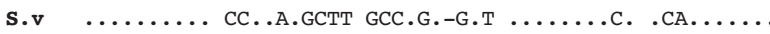

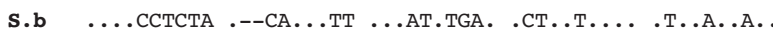
s.sc ....ССТСТА .--СА...Т. ...АТ.TGA. .СТ..Т... .Т....А.

s.s-1 TGAGAGTGTC CGCGCTAGCA GGTCTGTGAT GCCCTTAAAC ACTCTAGGCC 1150

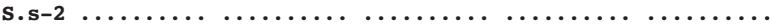

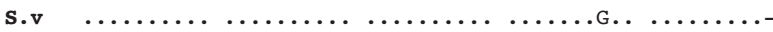

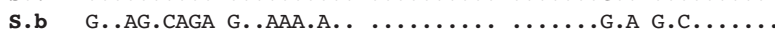
S.sc G..AG.CAGA G..AAA.A.................. G.C.....

s.s-1 GCACGCGTAC TACAATGGTA CG-GGCGAAG TCTCGCTTGG --TAGGAATA 1200

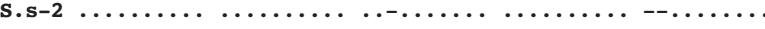
s.v $\quad \ldots \ldots \ldots \ldots$.....

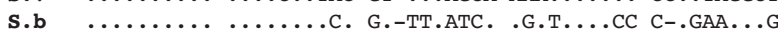

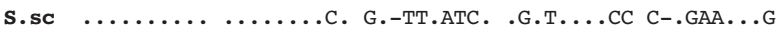

s.s-1 CCGAGCTATA CCGAACCCGT A-TCGTGGTT GGGACTGCAG GTTGGAATTC 1250

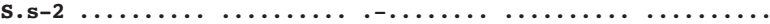

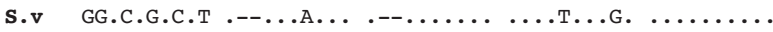
s.b GT.GCAG-.T .ATT.AAAC. TG...................... S.sc GT.GCAG-.T .ATT.AAAC. TG...........T............

s.s-1 TCCTGCACGA ACGAGGAATG TCTAGTAGGC CTGCATCATT ATtGCAAGCC 1300

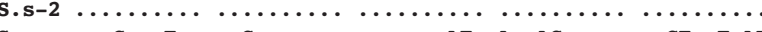

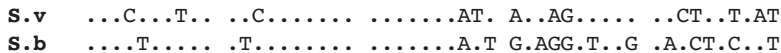

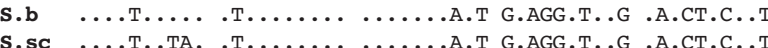

s.s-1 GACTACGTCC CTGTCTTTTG TACACACCGC CCGTCGCTCC TACCGATCCG 1350

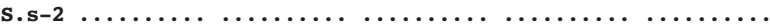
s.v $\quad \ldots$ G......G.........................

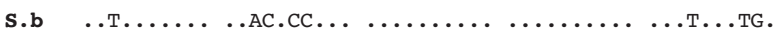

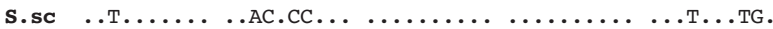

s.s-1 GCACTTTAGT TGAGTTGCGA GGAGC---GT TTA-CCTAC- GGTTG-ACGT 1400

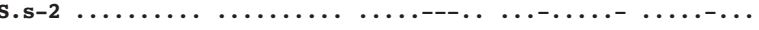

s.v .TGTGC.G......... . ... CGACCAG CGT-..AG.C ..С.СT.A.. s.b .A.GA.CT.G .......ATTC ...... CATAG G---TAAG.- АA..АTCT.. s.sc .A.GA.CT.G ......ATTC ...C.TACA. ..CGTA.-.- -...AT--.

s.s-1 GAATTGTCGC GAAGCTGC-A G------TG CTAGAGGAAG G 1441 s-2

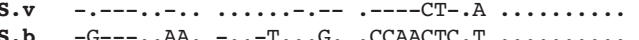

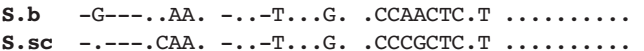


Fig. 5. Spironucleus spp. Alignment of partial ssu rRNA gene sequences from S. barkhanus (S.b) from wild Artic charr, 2 isolates of $S$. salmonis (S.s-1 and S.s-2) from farmed rainbow trout, S. salmonicida (S.sc) from farmed Atlantic salmon, and $S$. vortens (S.v) from angelfish. Differences from $S$. salmonis-1 sequence are given with the respective base. (.) Sequence similarities; (-) gaps. Accession Nos. S.b = AY646679; S.s-1 = DQ394703; S.s-2 = DQ394704; S.sc = AY677182; S.v = U93085

\section{Ultrastructural diagnosis}

The ultrastructure of the diplomonad from the German rainbow trout was consistent with that of Spironucleus salmonis from Irish rainbow trout as described by Poynton et al. (2004), with one exception. In the present study, although the cytoplasm at the posterior end of the cell was packed with free ribosomes, we did not see the 8-shaped sac of endoplasmic reticulum enclosing the ribosomes seen in some sections of $S$. salmonis from rainbow trout from Ireland (Poynton et al. 2004). This difference could be due to comparison of sections cut at different distances form the posterior end of the cell. Close to the posterior end, the endoplasmic sac

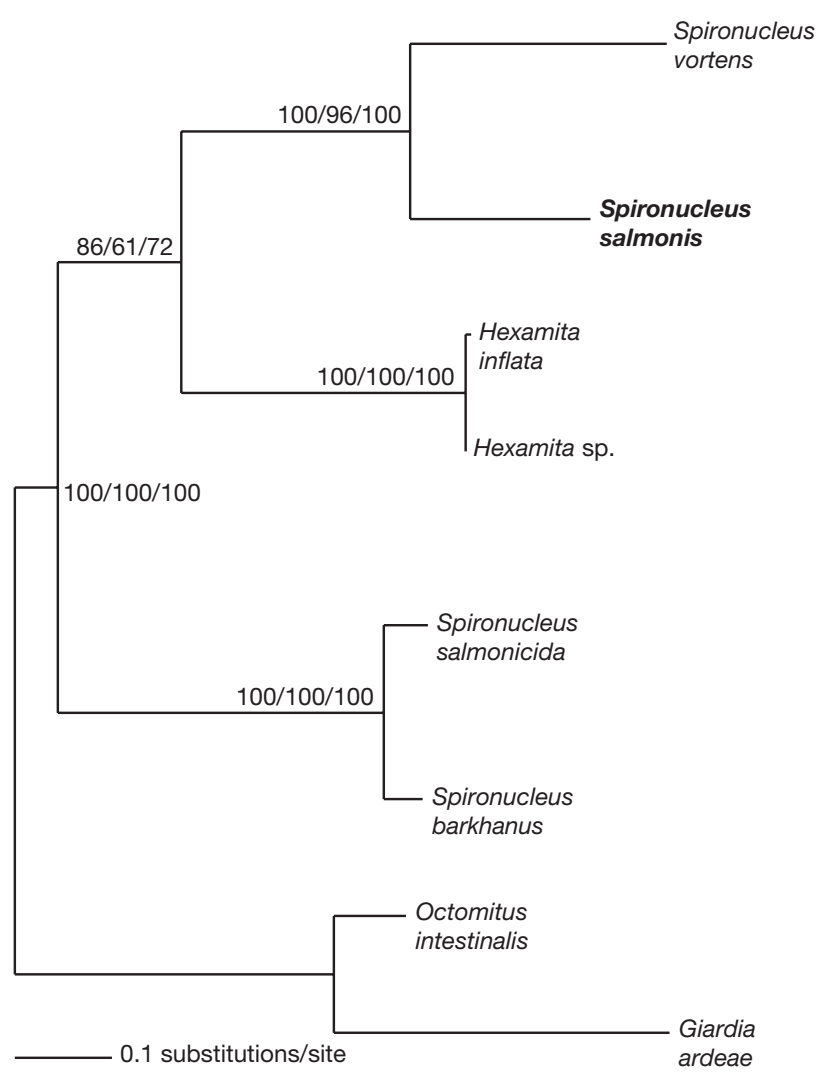

Fig. 6. Spironucleus salmonis phylogenetic position. Maximum likelihood analysis of selection of diplomonad taxa based on 1235 positions of small subunit (ssu) rRNA gene. Bootstrap values calculated using different tree-building methods are indicated at each node (maximum likelihood/ minimum evolution/maximum parsimony, respectively) was not present in S. salmonis from rainbow trout from Ireland (Fig. 5c in Poynton et al. 2004).

Previously, only internal ultrastructure has been used to distinguish Spironucleus salmonis from the other 3 well-characterised species of piscine diplomonads (Poynton et al. 2004). We now demonstrate that surface morphology can be used to distinguish species of piscine diplomonads. The unadorned surface of $S$. salmonis is distinct from that of $S$. vortens, which has a surface adorned with counter-crossing lateral ridges bearing tufts of microfibrils (Poynton et al. 1995). A caudal projection is borne by both $S$. salmonis and $S$. torosa; however, in $S$. salmonis there is a simple tapering posterior end, whereas in $S$. torosa the posterior end bears 2 raised ring-shaped structures (tori) (Poynton \& Morrison 1990); S. barkhanus does not bear a caudal projection, but 2 crescent-shaped structures (barkhans) (Sterud et al. 1997).

\section{Phylogenetic analyses}

The sequence of the Spironucleus salmonis ssu rRNA gene is given for the first time. The ssu rDNA sequence from $S$. salmonis could be clearly distinguished from all other sequenced Spironucleus spp. from fish. Sequencing the ssu rRNA gene therefore holds promise as a rapid method for identification of Spironucleus species from fish. The genetic differences observed between the isolates and the clones from the 2 German rainbow trout sampled in this study were probably due to amplification of different copies of the ssu rRNA gene, as observed by Keeling \& Doolittle (1997) and Jørgensen \& Sterud (2004). These differences may also be due to the lack of proof-reading of the Taq polymerase (Cline et al. 1996).

Our phylogenetic analyses recovered Spironucleus salmonis as the closest relative to $S$. vortens. Based on the morphology of these 2 taxa, this was somewhat surprising. S. vortens has a rather complex adorned surface (Poynton \& Morrison 1990, Sterud \& Poynton 2002), while S. salmonis is completely unadorned: this unadorned surface is more similar to that of $S$. barkhanus and S. salmonicida. However, the paraphyly of Spironucleus suggests that $S$. barkhanus and S. salmonicida are only distantly related to $S$. salmonis. This may be due to the increased rate of evolution observed for the diplomonads (Stiller \& Hall 1999). 
The basal position of Spironucleus barkhanus and S. salmonicida indicates that the unadorned surface probably is an ancestral state in Spironucleus, while the adorned surface of $S$. vortens is a derived character. The paraphyly of Spironucleus is consistent with descriptions in previous studies (Keeling \& Doolittle 1997, Kolisko et al. 2005).

Discussing the ultrastructural similaries between Spironucleus salmonis and $S$. barkhanus, Poynton et al. (2004) kept the option open that these species could subsequently be synonymised. The present results show that their decision to retain them as separate species was correct.

\section{Functional morphology}

Discharge of vacuoles (presumably containing waste digesta), at the surface of the body of Spironucleus salmonis has now been confirmed by SEM. Our present and previous study (Poynton et al. 2004) indicate that the vacuoles can be discharged from regions with the heterogenous cytoplasm. Discharged vacuoles are not visible at the apex of the cell (where the cytoplasm is homogenous), nor at the extreme posterior of the cell (where there are densely packed ribsomes), nor along the flagellar pockets. Although there are few detailed studies on feeding and digestion in Spironucleus species, it is known that these flagellates are phagotrophic, and endocytosis is reported to take place at the top of the flagellar pocket (Kulda \& Nohynkova 1978). However, the excretion of digestion products does not appear to have been documented. Discharging of digestive vacuoles has not been reported in other species of piscine diplomonads, suggesting different mechanisms of voiding the products of digestion. The cell surface of $S$. salmonis was confirmed as a simple plasma membrane (a Type I cell surface, according to the new classification of Becker 2000).

Examination of electron micrographs of piscine diplomonads shows that each has a distinct caudal morphology, with separated emerging recurrent flagella. Spironucleus barkhanus bears barkhans, which deflect the emerging flagella away from each other (Sterud et al. 1997), S. torosa bears a long caudal projection with flagella emerging some distance from the tip (Poynton \& Morrison 1990, Sterud 1998a,b), and $S$. vortens has broad counter-crossing lateral ridges with flagella emerging posterior-laterally (Poynton et al. 1995, Sterud \& Poynton 2002). Consideration of non-piscine Spironucleus species also shows separated emerging recurrent flagella. For example in $S$. meleagridis and $S$. muris (infecting game birds and mice, respectively), the flagella emerge posterior-laterally, some distance from the posterior end of the cell, spi- ralling away from each other (Cooper et al. 2004 and Branke et al. 1996, respectively). Similarly, piscine diplomonads have distinct surface morphology, in $S$. barkhanus, S. salmonis and $S$. torosa this is simple, whereas in $S$. vortens this is complex.

We suggest that the lobes, which entwine the Spironucleus salmonis nuclei (Fig. 2b,c,e), are formed in response to the rigorous action of the closely apposed anterior-medial kinetosomes. The distally directed beats of the anterior flagella will be associated with movement of the kinetosomes (the bases of which are secured in reinforced depressions in the nuclear membrane, i.e. the kinetosomal pockets), and this may results in compensatory hydrostatic pressure within the nucleoplasm resulting in lobe formation. Lobes were present both adjacent to the kinetosomal pockets, and where the nuclei were apposed to each other. The entwined lobes should confer mechanical strength and integrity to the 2 nuclei and, in turn, provide stability for the anterior kinetosomes. Such mechanical strength and integrity would be advantageous, given that the apex of the Spironucleus cell is exposed to considerable internal mechanical forces, generated by the distally directed beats of the anterior flagella arising from the anterior-medial kinetosomes. We suggest that the deformability of the lobes depends upon the phase of the flagellar beat, and the rigour of the beat, which will be affected by such factors as the viscosity of the liquid through which the diplomonads swim.

Lobed nuclei are present in other piscine Spironucleus species ( $S$. barkhanus, Sterud et al. 1997, 2003; S. vortens, Poynton et al. 1995, Sterud \& Poynton 2002; S. torosa, Poynton \& Morrison 1990, Sterud 1998a; and in Hexamita nobilis, Li 1995, a possible Spironucleus species, see 'Introduction'), although previous investigators have not commented upon their possible functional morphology. The nuclei of Hexamita species (Brugerolle 1974) and Octomitus species (Brugerolle et al. 1974) are not lobed and intertwined, but are simply appressed medially. Both these genera have anterior-lateral kinetosomes; thus, movement of the 2 clusters of kinetosomes will not produce intertwined lobes in overlapping nuclei. Furthermore, the apex of Hexamita and Octomitus cells may be subject to less internal mechanical stress than is the case in Spironucleus, which has anterior-medial kinetosomes.

We observed aggregates of glycogen extending longitudinally between the flagellar pocket and the striated lamina - an unusual location. The aggregated glycogen may have been transported to this location with other cytoplasmic components when the flagella pocket and the striated lamella were forming.

The present study of the dense bodies in the cytoplasm of Spironucleus salmonis, particularly their 
apparent 'budding' (Fig. 4b), is consistent with the secretory function previously suggested by Poynton et al. (2004).

\section{Host and geographical record}

There are numerous reports of diplomonads in fish in Germany, including one of the earliest reports of infection in trout (Schmidt 1919), and an extended study of ecology and host specificity of a diplomonad originally called Hexamita salmonis and now more correctly called Spironucleus salmonis (Sanzin 1965). Widely used fish pathology textbooks in Germany refer to Hexamita infections in salmonids (Roberts \& Schlotfeldt 1985, Schäperclaus et al. 1990, Schlotfeldt 1991). However, comprehensive ultrastructural and molecular approaches for accurate identification of the parasites do not appear to have been used previously, and therefore the true identity of the parasites in these prior publications remains unknown.

Our present study has demonstrated the presence of Spironucleus salmonis in a fish farm near Berlin. However, we do not imply that $S$. salmonis is a parasite newly introduced to Germany, but rather that we have now - with modern techniques - assigned the correct name to the flagellate at this particular farm, which would probably have otherwise be referred to as Hexamita salmonis or Octomitus truttae. However, we emphasis that the name $S$. salmonis should only be used when a proper identification has been made using the comprehensive techniques described in the present paper. In the absence of ultrastructural and/or molecular characterisations, parasites should be recorded simply as diplomonads, since even genus cannot be adequately determined by light microscopy (Poynton \& Sterud 2002).

\section{Recommendation}

We recommend that future studies of piscine diplomonads include not only ultrastructure, but also molecular characterisation.

Acknowledgements. Mr. Wilschinsky (Director of Seltershof farm, Berlin) is thanked for supplying fish. Dr. Bernhard Rennert and Mr. Mathias Kunow (Leibniz-Institute for Freshwater Ecology and Inland Fisheries, Berlin) are most warmly thanked for their logistical support, and Professor Dr. Carsten Schulz (Humboldt University, Berlin) for helpful discussion about rainbow trout aquaculture. Ms. Anorte Marko (Molecular Parasitology, Humboldt University, Berlin) graciously undertook initial sample processing of electron microscopy samples. Mr. Michael Delannoy (Johns Hopkins University, School of Medicine, Baltimore), and Ms. Else Engeland (National Veterinary Institute, Oslo) also processed some TEM samples. Ms. Vera Henke (Leibniz-Institute for Freshwater Ecology and Inland Fisheries, Berlin, IGB) carefully scanned the electron microscopy figures. Ms. Claudia Weisheit and Ms. Jaiwei Cheng kindly translated articles (from German and Chinese, respectively). Dr. Klaus Knopf and Dr. Klaus Kohlmann (IGB) kindly revised the manuscript. We gratefully acknowledge the Promotionsförderung des Landes BerlinNaFöG for the award of a PhD Scholarship to Mr. M. Reza Saghari Fard, and the Deutsche Forschungsgemeinschaft for the award of a Mercator Visiting Professorship to Dr. Sarah L. Poynton.

\section{LITERATURE CITED}

Becker B (2000) The cell surface of flagellates. In: Leadbeater SC, Green JC (eds) The flagellates. Taylor \& Francis, London, p 110-123

Brämick U (2004) Binnenfischerei 2003. In: Dölling R (ed) Jahresbericht über die Deutsche Fischwirtschaft 2004. Bunderministerium für Verbraucherschutz, Ernährung und Landwirtschaft, DCM Verlag, Meckenheim, p 47-77

Branke J, Berchtold M, Breunig A, König H (1996) 16S-like rDNA sequence and phylogenetic position of the diplomonad Spironucleus muris (Lavier 1936). Eur J Protistol 32: $227-233$

Brugerolle G (1974) Contribution a l'étude cytologique et phylétique des diplozoaires (Zoomastigophorea, Diplozoa; Dangeard 1910). III. Étude ultrastructurale du genre Hexamita (Dujardin 1836). Protistologica 10:83-90

Brugerolle G, Joyon L, Oktem N (1973) Contribution a l'étude cytologique et phylétique des diplozoaires (Zoomastigophorea, Diplozoa; Dangeard 1910). II. Étude ultrastructurale du genre Spironucleus (Lavier 1936). Protistologica 9: 495-502

Brugerolle G, Joyon L, Oktem N (1974) Contribution a l'étude cytologique et phylétique des diplozoaires (Zoomastigophorea, Diplozoa; Dangeard 1910). III. Étude ultrastructurale du genre Octomitus (Prowazek 1904). Protistologica 10: $457-463$

Buchmann K, Bresciani J (2001) An introduction to parasitic diseases of freshwater trout. DSR Publishers, Frederiksberg $\mathrm{C}$

Cline J, Braman JC, Hogrefe HH (1996) PCR fidelity of pfu DNA polymerase and other thermostable DNA polymerases. Nucleic Acids Res 24:3546-3551

Cooper GL, Charlton BR, Bickford AA, Nordhausen R (2004) Hexamita meleagridis (Spironucleus meleagridis) infection in Chukar partridges associated with high mortality and intracellular trophozoites. Avian Dis 48:706-710

Cunningham CO (2002) Molecular diagnostics of salmonid diseases. Kluwer, Dordrecht

Davis HS (1926) Octomitus salmonis, a parasitic flagellate of trout. Bull Bur Fish Wash 42:9-26

FAO (2004) FAO yearbook. Fishery statistics. Aquaculture production 94/2. FAO, Rome.

Ferguson HW (1979) Scanning and transmission electron microscopical observation on Hexamita salmonis (Moore, 1922) related to mortalities in rainbow trout fry Salmo gairdneri Richardson. J Fish Dis 2:57-67

Hall TA (1999) BioEdit: a user-friendly biological sequence alignment editor and analysis program for Windows 95/98/NT. Nucleic Acids Symp Ser 41:95-98

Hilge V (2004) Aquakultur im Binnenland und in den Küstengewässern. Fisch Teichwirt 5:663-666

Jørgensen A, Sterud E (2004) ssu rRNA gene sequence reveals two genotypes of Spironucleus barkhanus (Diplo- 
monadida) from farmed and wild Arctic charr Salvelinus alpinus. Dis Aquat Org 62:93-96

Jørgensen A, Sterud E (2006) The marine pathogenic genotype of Spironucleus barkhanus from farmed salmonids redescribed as Spironucleus salmonicida n. sp. J Eukaryot Microbiol 53:531-541

Keeling PJ, Doolittle WF (1997) Widespread and ancient distribution of a noncanonical genetic code in diplomonads. Mol Biol Evol 14:895-901

Kent ML, Ellis J, Fournie JW, Dawe SC, Bagshaw JW, Whitaker DJ (1992) Systemic hexamitid (Protozoa: Diplomonadida) infection in seawater pen-reared Chinook salmon Oncorhynchus tshawytsha. Dis Aquat Org 14:81-89

Kolisko M, Cepicka I, Hampl V, Kulda J, Flegr J (2005) The phylogenetic position of enteromonads: a challenge for the present models of diplomonad evolution. Int J Syst Evol Microbiol 55:1729-1733

Kulda J, Nohynkova E (1978) Flagellates of human intestine and of intestines of other species. In: Kreier JP (ed) Parasitic protozoa, Vol 2. Academic Press, New York, p 2-138

Li LX (1995) Ultrastructural observation on the Hexamita nobilis. Acta Hydrobiol Sin 19:263-268

Moore E (1922) Octomitus salmonis, a new species of intestinal parasite in trout. Trans Am Fish Soc 52:74-97

Poppe TT, Mo TA, Iversen L (1992) Disseminated hexamitosis in sea-caged Atlantic salmon Salmo salar. Dis Aquat Org 14:91-97

Posada D, Crandall KA (2001) Selecting the best-fit model of nucleotide substitution. Syst Biol 50:580-601

Poynton SL, Morrison CM (1990) Morphology of diplomonad flagellates: Spironucleus torosa n. sp. from Atlantic cod Gadus morhua L., and haddock Melanogrammus aeglefinus (L.) and Hexamita salmonis Moore from brook trout Salvelinus fontinalis (Mitchill). J Protozool 37:369-383

Poynton SL, Sterud E (2002) Guidelines for species descriptions of diplomonad flagellates from fish. J Fish Dis 25:15-31

Poynton SL, Fraser W, Francis-Floyd R, Rutledge P, Reed P, Nerad TA (1995) Spironucleus vortens n. sp. from freshwater angel fish Pterophyllum scalare: morphology and culture. J Eukaryot Microbiol 42:731-742

Poynton SL, Saghari Fard MR, Jenkins J, Ferguson HW (2004) Ultrastructure of Spironucleus salmonis n. comb. (formerly Octomitus salmonis sensu Moore 1922, Davis 1926, and Hexamita salmonis sensu Ferguson 1979), with a guide to Spironucleus species. Dis Aquat Org 60:49-64

Roberts RJ (1989) Fish pathology, 2nd edn. Baillière Tindall, London

Roberts RJ, Schlotfeldt HJ (1985) Grundlagen der Fischpathologie mit einer Einführung in die Anatomie, Physiologie, Pathophysiologie und Immunologie sowie in den aquatischen Lebensraum der Knochenfische. Paul Parey, Berlin

Roberts RJ, Shepherd CJ (1979) Handbook of trout and salmon diseases. Fishing News Books, Farnham

Sano (1970) Etiology and histopathology of hexamitiasis and an IPN-like disease of rainbow trout. J Tokyo Univ Fish 56: $23-30$

Sanzin WD (1965) Untersuchungen zur Ökologie, Artspezifität und Variabilität von Hexamita salmonis Moore. PhD

Editorial responsibility: Dieter Steinhagen,

Hannover, Germany dissertation, Ludwig-Maximilians University of Munich Schäperclaus W, Kulow H, Schreckenbach K (1990) Fischkrankheiten, Teil 2. Akademie-Verlag, Berlin

Schlotfeldt HJ (1991) Was tun, wenn ...? ein Leitfaden für den praktischen Fischzüchter, Teichwirt und Fischhalter. Staatlichen Fischseuchenbekämpfungsdienstes Niedersachsen und Fischgesundheitsdienstes, Hannover

Schlotfeldt HJ, Alderman DJ (1995) What should I do? A practical guide for the freshwater fish farmer. Bull Eur Assoc Fish Pathol (Suppl) 15

Schmidt W (1919) Untersuchung über Octomitus intestinalis truttae. Arch Protistenkd 40:253-289

Seligo A (1887) Untersuchungen über Flagellaten. Beitr Biol Pflz 4:145-180

Sterud E (1998a) Electron microscopical identification of the flagellate Spironucleus torosa (Hexamitidae) from burbot Lota lota (Gadidae) with comments upon its probable introduction to this freshwater host. J Parasitol 84: 947-953

Sterud E (1998b) Ultrastructure of Spironucleus torosa Poynton \& Morrison, 1990 (Diplomonadida: Hexamitidae), in cod Gadus morhua (L.) and saithe Pollachius virens (L.) from south-eastern Norway. Eur J Protistol 34:69-77

Sterud E, Poynton SL (2002) Spironucleus vortens (Diplomonadida) in the ide, Leuciscus idus (L.) (Cyprinidae): a warm water hexamitid flagellate found in Northern Europe. J Eukaryot Microbiol 49:137-145

Sterud E, Mo TA, Poppe TT (1997) Ultrastructure of Spironucleus barkhanus $\mathrm{n}$. sp. (Diplomonadida: Hexamitidae) from grayling Thymallus thymallus (L.) (Salmonidae) and Atlantic salmon Salmo salar L. (Salmonidae). J Eukaryot Microbiol 44:399-407

Sterud E, Mo TA, Poppe TT (1998) Systemic spironucleosis in sea-farmed Atlantic salmon Salmo salar, caused by Spironucleus barkhanus transmitted from feral Arctic char Salvelinus alpinus? Dis Aquat Org 33:63-66

Sterud E, Poppe T, Bornø G (2003) Intracellular infection with Spironucleus barkhanus (Diplomonadida: Hexamitidae) in farmed Arctic charr Salvelinus alpinus. Dis Aquat Org 56: $155-161$

Stiller JD, Hall BD (1999) Long-branch attraction and the rDNA model of early eukaryotic evolution. Mol Biol Evol 16: 1270-1279

Swofford DL (2002) PAUP*: phylogenetic analysis using parsimony ( ${ }^{*}$ and other methods), Version 4 . Sinauer, Sunderland, MA

Uzmann JR, Paulik GJ, Hayduk SH (1965) Experimental hexamitiasis in juvenile coho salmon (Oncorhynchus kisutch) and steelhead trout (Salmo gairdneri). Trans Am Fish Soc 94:53-61

Woo PTK, Poynton SL (1995) Diplomonadida, Kinetoplastida and Amoebida (phylum Sarcomastigophora). In: Woo PTK (ed) Fish diseases and disorders, Vol 1. Protozoan and metazoan disorders. CAB International, Wallingford, p 27-96

Xiao W, Li L (1994) A light and transmission electron microscopic study of Hexamita capsularis sp. nov. (Diplomonadida: Hexamita) in fish (Xenocypris divide). Chin J Oceanol Limnol 12:208-212

Submitted: March 31, 2006; Accepted: November 16, 2006 Proofs received from author(s): March 14, 2007 